\title{
USO DE EMBALAGENS PLÁSTICAS E COBERTURA DE QUI- TOSANA NA CONSERVAÇÃO PÓS-COLHEITA DE LICHIAS ${ }^{1}$
}

\author{
ELLEN TOEWS DOLL HOJO², JOSÉ FERNANDO DURIGAN², RONALDO HISSAYUKI HOJO²
}

RESUMO - Objetivou-se avaliar a efetividade da atmosfera modificada, através de embalagens plásticas e coberturas de quitosana, na conservação pós-colheita de lichias. O delineamento estatístico foi o inteiramente casualizado, disposto em esquema fatorial $5 \times 7$, com 3 repetições, onde o primeiro fator corresponde aos tratamentos: Testemunha; Bandejas rígidas de poliestireno revestidas com filme poliolefínico de $0,015 \mathrm{~mm}$ (PD955); Bandejas rígidas de polietileno tereftalato (PET); Bandejas de poliestireno recobertas com filme de cloreto de polivinila (PVC) de $0,014 \mathrm{~mm}$; e Imersão em quitosana a $0,5 \%$. O segundo fator foi o tempo de armazenamento, 0 (inicial); 4; 8; 12; 16; 20 e 24 dias, a $5{ }^{\circ} \mathrm{C}(94 \% \mathrm{UR})$. Cada parcela foi composta por 8 frutos, sendo que os tratados com quitosana foram contidos em bandejas rígidas de poliestireno, sem filme. Os resultados obtidos permitiram concluir que a proteção com filmes plásticos reduziu significativamente a perda de massa por lichias mantidas sob refrigeração, com redução na intensidade do escurecimento dos frutos. O tratamento com quitosana a $0,5 \%$, em ácido tartárico a $10 \%, \mathrm{pH} 0,8$, mostrou-se efetivo na manutenção da coloração vermelha e na prevenção ao escurecimento, conservando a aparência dos frutos. Termos para indexação: Litchi chinensis, escurecimento do pericarpo, quitosana, embalagens plásticas.

\section{USE OF PLASTIC PACKAGING AND COVERAGE OF CHITOSAN IN THE POSTHARVEST CONSERVATION OF LITCHI}

\begin{abstract}
The objective of the study was to evaluate the effectiveness of a modified atmosphere, by the use of plastic covers packaging and chitosan coverage in lychee postharvest storage. The experimental design was completely randomized in a factorial $5 \times 7$, with 3 replications, where the first factor corresponds to the treatments: control; rigid polystyrene trays $(22.4 \mathrm{~cm} \times 14.8 \mathrm{~cm})$ coated with a $0.015 \mathrm{~mm}$ (PD955) polyolefin film (PF); 500ml transparent rigid polyethylene terephthalate (PET) trays with lid; polystyrene trays covered with $0.014 \mathrm{~mm}$ polyvinyl chloride (PVC) film; and immersion in $0.5 \%$ chitosan. The second factor was the storage time, 0 (initial), 4, 8, 12, 16, 20 and 24 days at $5{ }^{\circ} \mathrm{C}, 94 \% \mathrm{RH}$. Each plot consisted of eight fruits, and those treated with chitosan were placed in rigid polystyrene trays without film. The results showed that the modified atmosphere reduced significantly the mass loss of fruits stored under refrigeration, especially with PVC film. Chitosan $0.5 \%$ proved to be more effective in maintaining the red color and preventing browning, keeping the fruits more attractive.
\end{abstract}

Index terms: Litchi chinensis, pericarp browning, chitosan, plastic packages.

\section{INTRODUÇÃO}

O escurecimento do pericarpo é o principal problema pós-colheita da lichia. Embora seja somente uma injúria considerada "cosmética", que tem pouco ou nenhum efeito no sabor, mas torna os frutos não adequados para a comercialização em diversos mercados, principalmente na Europa e nos Estados Unidos (HOLCROFT; MITCHAM, 1996).

Este escurecimento está associado à dessecação (SCOTT et al., 1982), todavia o estresse por altas temperaturas, a senescência, os danos por frio, as pragas e as doenças também podem provocá-lo. Há, portanto, a necessidade de tecnologias que retardem este escurecimento, aumentando a vida útil pós-colheita e a qualidade comercial de lichias.

Dentre os métodos de conservação, a atmosfera modificada é utilizada para prolongar a vida de prateleira de frutas, que pode ser obtida pelo acondicionamento das mesmas em filmes plásticos ou pelo seu recobrimento com biofilmes (CHITARRA; CHITARRA, 2005). O emprego de filmes plásticos na conservação

\footnotetext{
${ }^{1}$ Trabalho Sinfruit 152 - Simpósio Internacional de Fruticultura - Avanços na Fruticultura (17 a 21 Outubro)

${ }^{2}$ Parte de tese de Doutorado em Agronomia do primeiro autor, apresentado ao Departamento de Produção Vegetal - FCAV -UNESP/ Jaboticabal.

${ }^{2}$ Pós-doutorandos em Fitotecnia. UESB - Câmpus de Vitória da Conquista. Estrada do Bem Querer, km 4, 45031-900, Vitória da Conquista - BA. E-mail: ellendollhojo@yahoo.com.br;

${ }^{3}$ Professor Titular do Departamento de Tecnologia FCAV/UNESP/ Jaboticabal. E-mail: jfduri@fcav.unesp.br
} 
pós-colheita de lichias tem sido testado por diversos autores, indicando a manutenção da qualidade de lichias 'Mauritius', 'Brewster'e 'Hong Huai' durante o armazenamento, pois reduziu o escurecimento do pericarpo dos mesmos (FONTES et al., 1999; CHAIPRASART, 2005; SIVAKUMAR; KORSTEN, 2006; SOMBOONKAEW; TERRY, 2010a; 2010b). A utilização de quitosana a $1 \%$ também foi testada e observaram-se perdas de massa fresca superiores a 3\%, em lichias 'Kway Mi' armazenadas por 10 dias (ZHANG; QUANTICK, 1997; CARO; JOAS, 2005; JOAS et al., 2005).

A atmosfera modificada também tem-se mostrado benéfica por impedir a perda de água e o consequente escurecimento do pericarpo (KADER, 1994; PESIS et al., 2002).

Este trabalho teve como objetivo avaliar a efetividade da atmosfera modificada, através de embalagens plásticas e revestimento com quitosana, na conservação pós-colheita de lichia.

\section{MATERIAL E MÉTODOS}

Foram utilizados frutos de lichia (Litchi chinensis Sonn.) 'Bengal', adquiridos de pomar localizado no município de Taquaritinga. Os frutos foram colhidos manualmente pela manhã, no estádio de maturação maduro (casca completamente avermelhada). Após a colheita, os frutos foram transportados até o Laboratório de Tecnologia dos Produtos Agrícolas da FCAV- UNESP, Câmpus de Jaboticabal - SP. Após seleção quanto ao tamanho, cor e ausência de injúrias, eles foram lavados e sanificados com hipoclorito de sódio a $200 \mathrm{mg} \mathrm{L}^{-1}$, por 5 minutos.

O delineamento estatístico foi o inteiramente casualizado, disposto em esquema fatorial $5 \times 7$, com 3 repetições, em que o primeiro fator correspondeu aos tratamentos: Testemunha (TEST); Embalagem em Bandejas rígidas de poliestireno $(22,4 \mathrm{~cm} \mathrm{x}$ $14,8 \mathrm{~cm}$ ) revestidas com filme poliolefínico (FP) de 0,015mm (Cry-O-Vac, PD955); Bandejas rígidas de polietileno tereftalato (PET) de $500 \mathrm{~mL}$ (Neoform N-90), transparente e com tampa; ou em bandejas de poliestireno $(22,4 \mathrm{~cm} \times 14,8 \mathrm{~cm})$ recobertas com filme de cloreto de polivinila (PVC) de $14 \mathrm{~mm}\left(\mathrm{Omnifim}^{\circledR}\right)$; e Imersão em quitosana ( $>90 \%$ de desacetilação, Sigma - Aldrich) a $0,5 \%$, por 30 segundos, e secagem ao ambiente $(\mathrm{Q} 0,5 \%)$. A quitosana foi diluída em ácido tartárico a $10 \%, \mathrm{pH}=0,8$. O segundo fator foi o tempo de armazenamento, 0 (inicial); 4; 8; 12,; 16; 20 e 24 dias, a $5{ }^{\circ} \mathrm{C}$ (94\%UR). Cada parcela foi composta por 8 frutos, sendo que os tratados com quitosana foram contidos em bandejas rígidas de poliestireno $(22,4 \mathrm{~cm} \times 14,8 \mathrm{~cm})$.
Os parâmetros avaliados foram: perda de massa fresca (\%), calculando-se a diferença entre a massa inicial do fruto e a obtida em cada intervalo de tempo do armazenamento, utilizando-se de balança semianalítica; aparência, avaliada visualmente, usando-se uma escala de notas, em que, $5=$ vermelho-brilhante; $4=25 \%$ da casca escurecida; $3=50 \%$ da casca escurecida; $2=75 \%$ da casca escurecida; e $1=$ totalmente escurecida. Na polpa, foram determinados os teores de sólidos solúveis, determinados em refratômetro digital ATAGO PR-100 (AOAC, 1997, proc. 920.151); acidez titulável, por titulação com $\mathrm{NaOH}$ a 0,1M (AOAC, 1997, proc. 932-12); e ácido ascórbico, usando-se 2,6 diclorofenolindofenol de sódio a $0,1 \%$ para titular o extrato obtido da polpa com ácido oxálico a $0,5 \%$, a $5{ }^{\circ} \mathrm{C}$ (RANGANNA, 1977). Na casca, determinou-se o teor de antocianina, tendo-se como extrator uma mistura de etanol a $95 \%$ e $\mathrm{HCl}$ a 1,5M (15:85, v:v), e determinação colorimétrica (FRANCIS, 1982). A atividade da peroxidase e da polifenoloxidase foram determinadas na casca e na polpa dos frutos, utilizando-se do sobrenadante de amostras homogeneizadas em tampão fosfato de potássio a $0,2 \mathrm{M}, \mathrm{pH} 6,7$ e centrifugadas a $11655 \mathrm{xg}$, por 10 minutos, a $4{ }^{\circ} \mathrm{C}$. A atividade da peroxidase foi determinada conforme o indicado por Lima et al. (1998), e a da polifenoloxidase, segundo o proposto por Allain et al. (1974). Os teores de $\mathrm{O}_{2}$ e $\mathrm{CO}_{2}$ no interior das embalagens foram determinados usando-se o analisador de gases, Checkmate 9900, PBI Dansensor. Nos frutos tratados com quitosana, os teores de $\mathrm{O}_{2}$ e $\mathrm{CO}_{2}$ em seus tecidos foram determinados usando-se o método indicado por Saltveit (1982).

Os dados obtidos foram submetidos à análise de variância, e a descrição das variáveis, em função dos períodos de armazenamento, foi feita utilizando-se da análise de regressão.

\section{RESULTADOS E DISCUSSÃO}

A perda de massa pelos frutos, durante o período de armazenamento, foi menor nos protegidos com a embalagem de PET $(0,27 \%)$, ou com os filmes, poliolefínico $(\mathrm{FP}=1,37 \%)$ e de cloreto de polivinila $(\mathrm{PVC}=1,52 \%)$. Nos tratados com quitosana a $0,5 \%(\mathrm{Q} 0,5 \%=18,51 \%)$, esta perda foi maior que nos frutos do Testemunha (13,14\%) (Figura 1A). A utilização das proteções plásticas reduziu a perda de peso pelos frutos, pois minimizou o déficit de pressão de vapor (DPV) entre os frutos e a atmosfera, e, consequentemente, limitou a perda de água por transpiração.

A película semipermeável de quitosana au- 
mentou esta perda, devido á sua natureza hidrofílica (KESTER; FENNEMA, 1988) e à reação adversa à epiderme do fruto, ocasionada pelos reagentes químicos presentes na formulação comercial da quitosana (ASSIS; LEONI, 2003), e utilizados em seu preparo.

Quanto à evolução da concentração de $\mathrm{O}_{2} \mathrm{e}$ $\mathrm{CO}_{2}(\%)$ no interior das embalagens, observou-se pequena variação nas concentrações do $\mathrm{O}_{2} \mathrm{em}$ todos os tratamentos, durante o período de armazenamento (Figura 2). Alguma redução no de $\mathrm{O}_{2}$ e aumento no de $\mathrm{CO}_{2}$ foi observada nas atmosferas modificadas com FP e PVC, que após dois dias estabilizaram os níveis de $\mathrm{O}_{2}$, nestes dois tratamentos média de 18,8\% (FP) e 19,1\% (PVC). Nos demais tratamentos-testemunha (PET), mantiveram-se os teores de $\mathrm{O}_{2}$ próximos a $21 \%$. Observou-se aumento no teor de $\mathrm{CO}_{2}$, que foi maior nas atmosferas modificadas com os filmes FP e PVC, nos 2-3 dias iniciais, que se estabilizaram em torno de 2,0-2,5\% no de PVC e poliolefínico (FP), enquanto na embalagem de PET estes se estabilizaram em torno de 1,0\%. De acordo com Chitarra e Chitarra (2005), após o acondicionamento do produto, a concentração de $\mathrm{O}_{2}$ no espaço livre da embalagem tende a decrescer, e a de $\mathrm{CO}_{2}$, a aumentar, em decorrência da respiração.

As concentrações de $\mathrm{O}_{2}$ e $\mathrm{CO}_{2}$ no interior das lichias dos tratamentos-testemunha e com quitosana a $0,5 \%$ mantiveram-se sem variações significativas ao longo do armazenamento, com os teores de $\mathrm{O}_{2}$ em torno de $16 \%$, e os de $\mathrm{CO}_{2}$, em $2,0 \%$. O filme formado pelo recobrimento de quitosana possibilitou de maneira efetiva, as trocas gasosas. Provavelmente, a fina camada formada pelo recobrimento de quitosana possibilitou que as trocas gasosas ocorressem, e de maneira efetiva, em manter as concentrações de $\mathrm{O}_{2}$ e $\mathrm{CO}_{2}$.

Os teores de sólidos solúveis na polpa dos frutos não variaram ao longo do período de armazenamento, ou não foram influenciados pelos tratamentos (Figura 1B), enquanto os de acidez titulável se reduziram durante o período de armazenamento (Figura 1C), como decorrência natural da evolução do amadurecimento, na qual os ácidos orgânicos são metabolizados na via respiratória (PECH, 2002).

A relação entre os teores de sólidos solúveis e acidez titulável aumentou durante o período de armazenamento, como efeito da manutenção nos teores de sólidos solúveis e redução na acidez titulável (Figura 1D).

Os teores de ácido ascórbico apresentaram-se com a maior redução nos frutos tratados com quitosana (Figura 1E). A diminuição observada em todos os tratamentos pode ser devido ao efeito deste ácido contrário ao das reações oxidativas que são ativadas durante a senescência do fruto (FOYER et al., 1994) e que foram mais estressados pela ação do ácido tartárico $(\mathrm{pH}=0,8)$ utilizado no preparo da quitosana.

A cor dos frutos do Testemunha apresentaram redução significativa na luminosidade e na cromaticidade, indicando escurecimento acentuado, conforme o relatado para a aparência (Figuras 3A, 3B e 3C). A redução na luminosidade dos frutos sob atmosfera modificada por filmes plásticos foi muito pequena, enquanto a redução na cromaticidade foi menor que nos do Testemunha. Estes frutos apresentaram valores semelhantes de ângulo hue (Tabela 1). Nos frutos tratados com quitosana, a redução na luminosidade foi semelhante à dos frutos protegidos com filmes plásticos, enquanto a cromaticidade se manteve nos valores iniciais e os valores do ângulo hue significativamente menores que o dos outros tratamentos, indicando a manutenção da cor vermelha.

Nos frutos do Testemunha, o escurecimento da casca prejudicou significativamente a aparência (Figura 3C), enquanto as proteções plásticas proporcionaram proteção inicial, que se agravou a partir de $8-12$ dias de armazenamento, com o aparecimento de manchas escuras.

Nos tratados com quitosana, aparência inicial foi conservada até o final do armazenamento. Os resultados obtidos indicam que o melhor tratamento para a manutenção dos teores de antocianina na casca dos frutos de lichia foi a imersão em quitosana a $0,5 \%$ (Figura 3D), reafirmando o indicado pela aparência (Figura 3C) e coloração (Figuras 3A, 3B e 3C e Tabela 1). Os frutos que foram protegidos com os filmes plásticos apresentaram redução significativa neste teor, mas não tão intensa quanto ao ocorrido nos do Testemunha.

A baixa degradação da antocianina nos frutos tratados com quitosana não pode ser atribuída à redução na atividade da polifenoloxidase ou da peroxidase (Figuras $3 \mathrm{E}$ e $3 \mathrm{~F}$ ) ou à perda de massa fresca (Figura 1A).

O efeito do escurecimento da lichia tem sido atribuído à desidratação, que aumenta o $\mathrm{pH}$ das células (UNDERHILL et al.,1997), o que não foi o observado neste trabalho.

A conservação dos teores de antocianina é atribuída à alta acidez da solução de quitosana em ácido tartárico $(\mathrm{pH}=0,8)$, pois a estrutura e a cor da antocianina são dependentes das condições ambientais das células, particularmente do $\mathrm{pH}$, da presença de íons e de moléculas fenólicas (HOLCROFT; MITCHAM, 1996).

Nos frutos protegidos com filmes, principalmente com o de PVC, o menor escurecimento está 
associado à menor atividade da PPO e da POD (Figuras $3 \mathrm{E}$ e F) e à menor perda de massa (Figura $1 \mathrm{~A}$ ), em relação ao Testemunha. Há evidências de que a atuação da PPO sobre o escurecimento da lichia é indireto e que ela é ativada pela perda de umidade dos frutos (TAYLOR, 1993). Este efeito também foi observado por Ducamp-Collin et al. (2008) ao tratar lichias 'Guiwei' e 'Huaizhi' com quitosana a $0,75 \%$, dissolvida em ácido cítrico a $60 \%$ e arma- zenadas a $4{ }^{\circ} \mathrm{C}$ e $90 \% \mathrm{UR}$, por 21 dias. As cultivares apresentaram respostas diferentes aos tratamentos, e, de modo geral, as tratadas com quitosana apresentaram redução nos teores de antocianina, sem impedir aumento na atividade de PPO ou da POD, durante o armazenamento. A acidificação do meio parece ter efeito significativo na preservação da antocianina e na inibição das enzimas oxidativas.
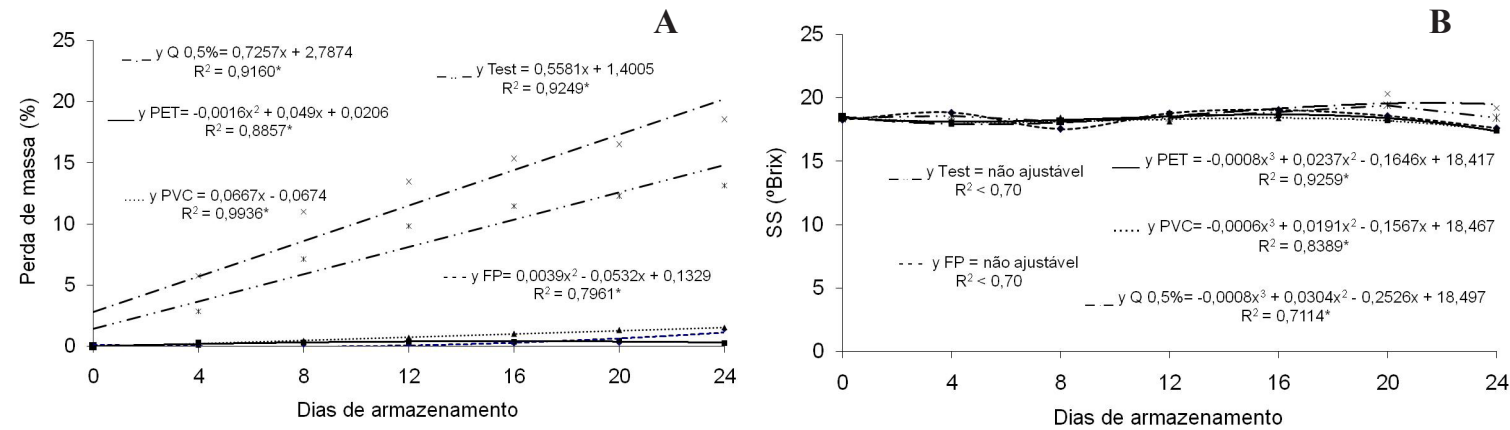

C

D
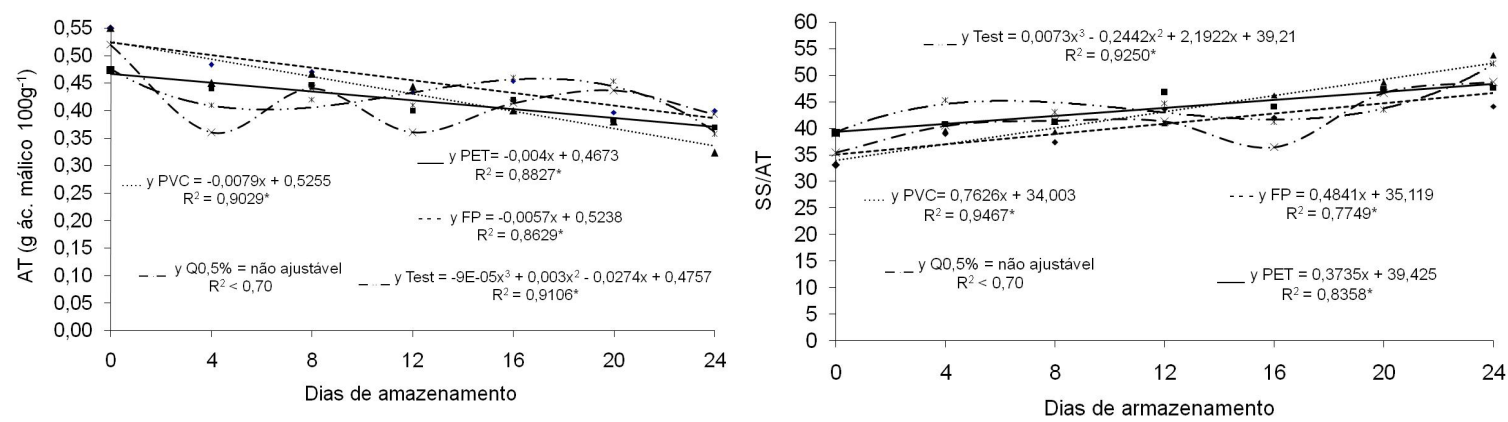

$\mathbf{E}$

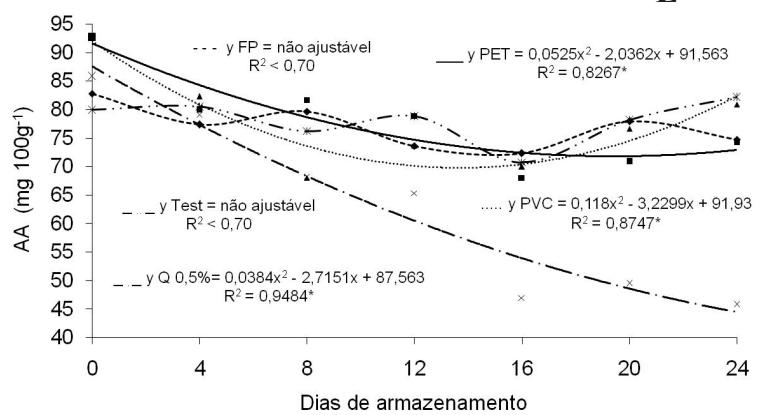

FIGURA1 - Perda de massa (A), teores de sólidos solúveis - SS (B), acidez titulável - AT (C), SS/AT (D) e teor de ácido ascórbico - AA (E) na polpa de lichias 'Bengal', armazenadas sob atmosfera modificada, a $5^{\circ} \mathrm{C}(94 \% \mathrm{UR})$. 

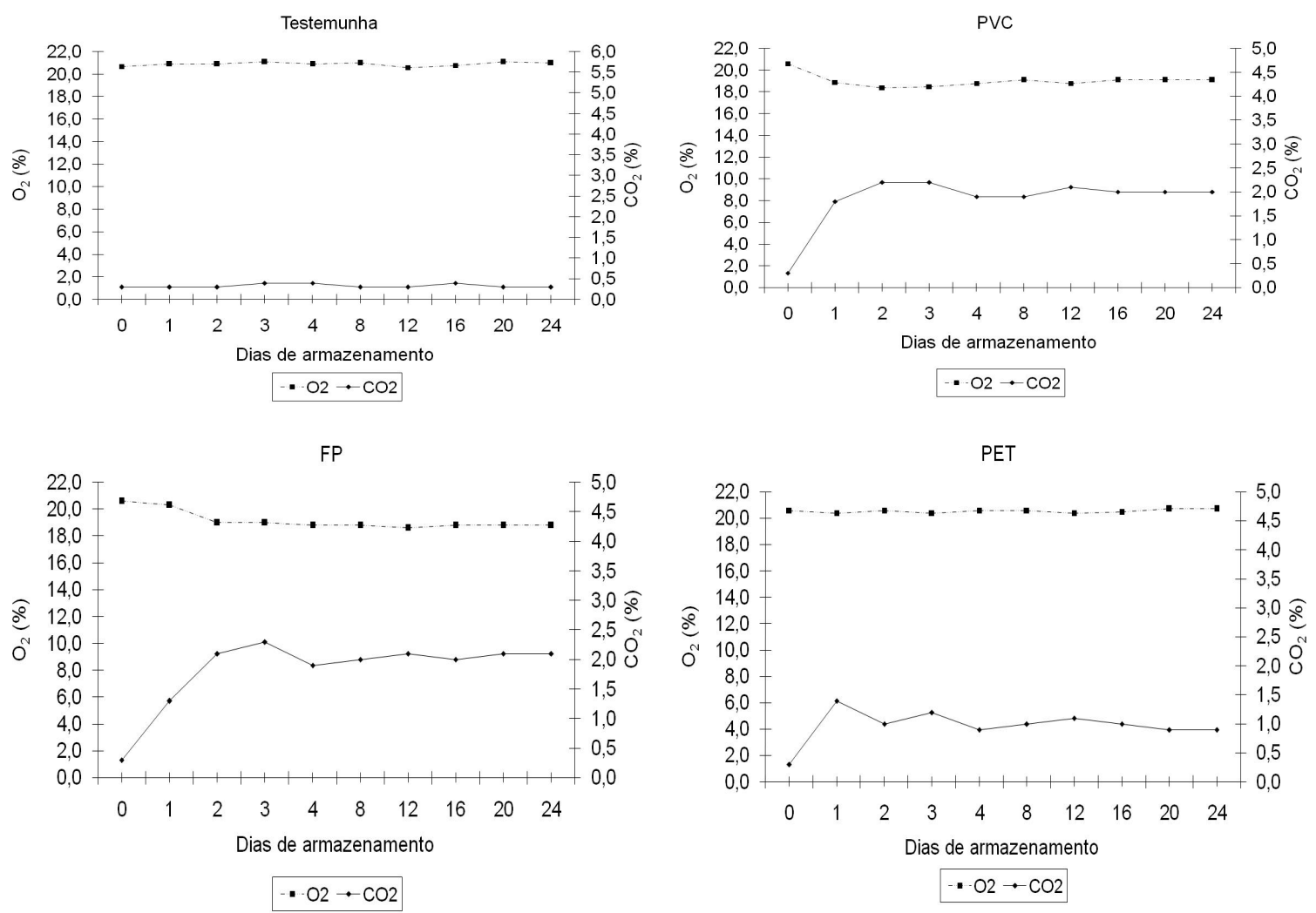

FIGURA 2 - Concentração de $\mathrm{O}_{2}$ e $\mathrm{CO}_{2}$ no interior das embalagens contendo lichias 'Bengal' e armazenadas a $5{ }^{\circ} \mathrm{C}(94 \% \mathrm{UR})$.

TABELA 1 - Ângulo hue da casca de lichias 'Bengal', armazenadas sob atmosfera modificada, a $5{ }^{\circ} \mathrm{C}(94$ $\%$ UR), por 24 dias.

\begin{tabular}{lc}
\hline Tratamento & Ângulo hue \\
\hline Testemunha & $29,39 \mathrm{a}$ \\
FP & $29,61 \mathrm{a}$ \\
PET & $29,27 \mathrm{a}$ \\
PVC & $29,60 \mathrm{a}$ \\
Q $0,5 \%$ & $25,74 \mathrm{~b}$ \\
\hline C.V. $(\%)$ & 7,28 \\
\hline
\end{tabular}

Médias seguidas de mesma letra não diferem entre si, pelo teste de Tukey $(P<0,05)$.
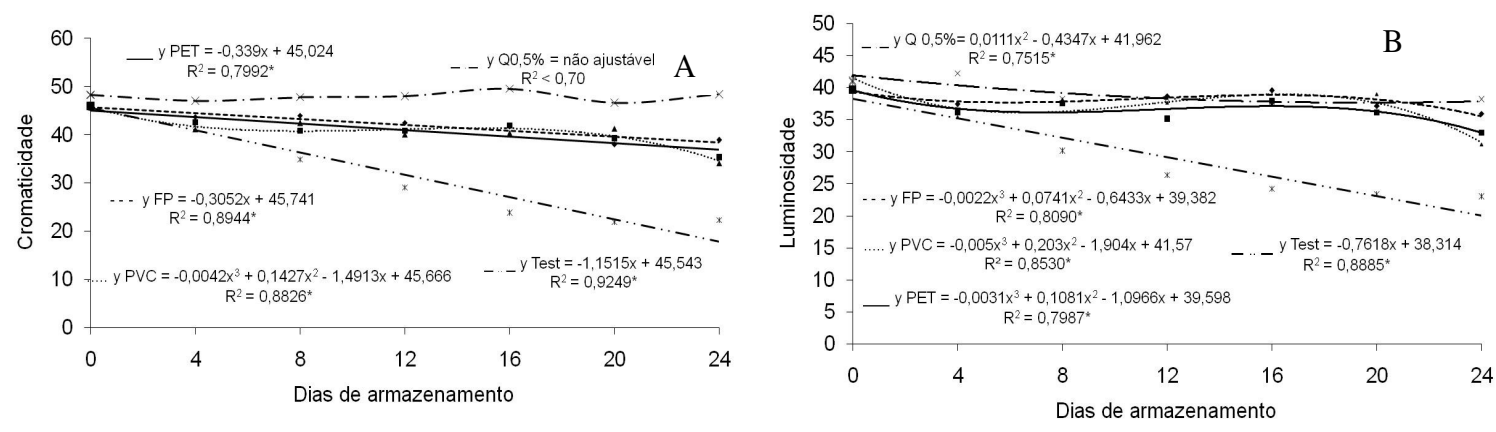

continua... 
continuação
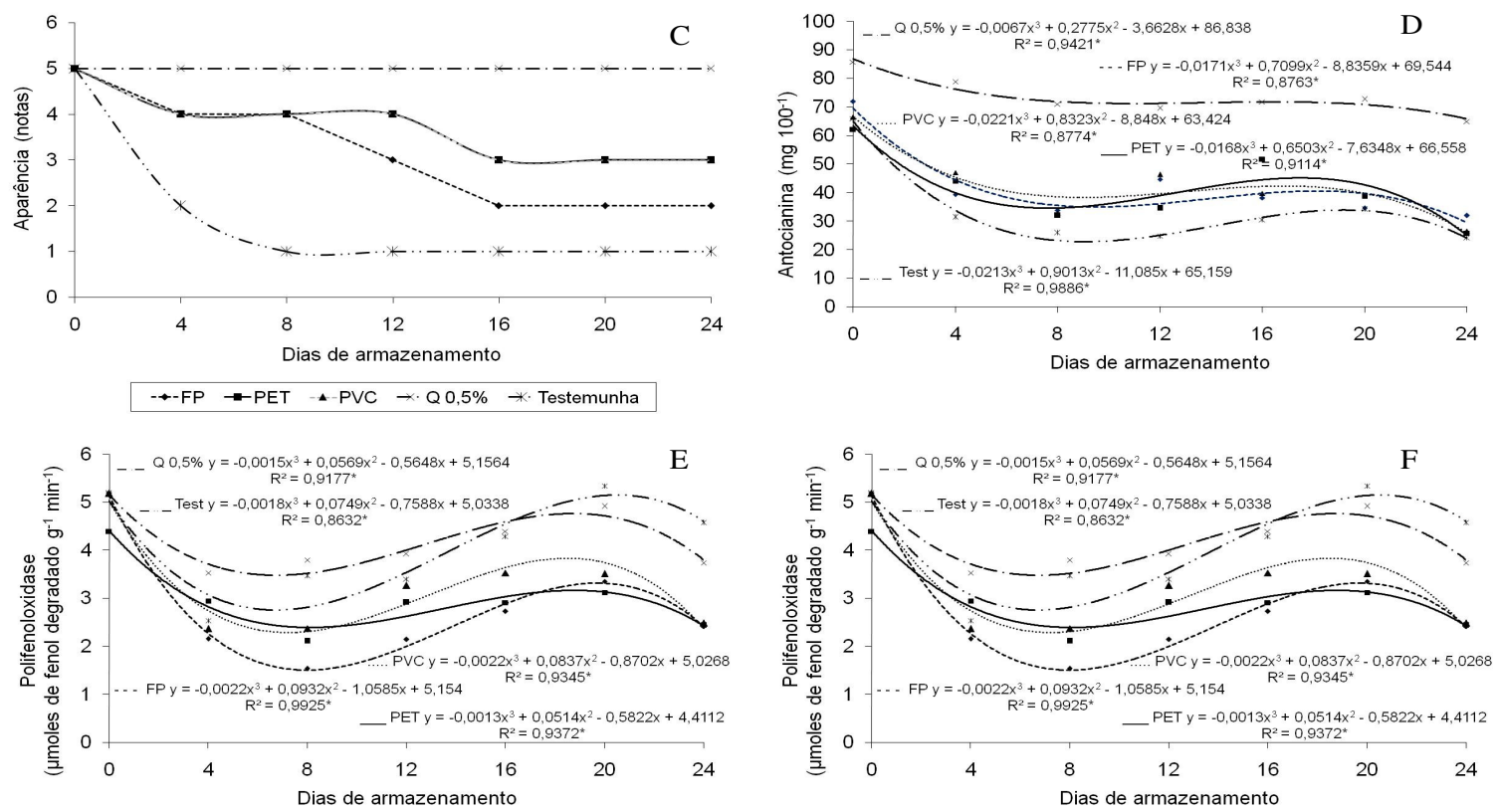

FIGURA 4 - Cromaticidade (A), luminosidade (B), aparência (C), teor de antocianina (D), e atividade de polifenoloxidase (E) e peroxidase (F) em lichias 'Bengal', armazenadas sob atmosfera modificada, a $5{ }^{\circ} \mathrm{C}(94 \% \mathrm{UR})$. (Notas: $5=$ vermelho-brilhante; $4=25 \%$ da casca escurecida; $3=50 \%$ da casca escurecida; $2=75 \%$ da casca escurecida; e $1=$ completamente escurecida).

\section{CONCLUSÕES}

1 - A proteção com filmes plásticos reduziu significativamente a perda de massa por lichias mantidas sob refrigeração, com redução na intensidade do escurecimento dos frutos.

2 - O tratamento com quitosana a $0,5 \%$ em ácido tartárico a $10 \%, \mathrm{pH} 0,8$, mostrou-se efetivo na manutenção da coloração vermelha e na prevenção ao escurecimento, conservando a aparência dos frutos.

\section{AGRADECIMENTOS}

À FAPESP(Processo 07/57351-9) e ao CNPq, pela concessão de bolsa de doutorado.

\section{REFERÊNCIAS}

ALLAIN, C. C.; POON, L. S.; CHAN, C. S. G.; RICHMOND, W.; FU, P.C. Enzymatic determination of total serum colesterol. Clinical Chemistry, Baltimore, v. 120, p. 470-475, 1974.

A.O.A.C. Official methods of analysis of the Association of Official Analytical Chemists International. Arlington: Patrícia Cuniff, 1997. p.37-10, 42-2, 44-3, 45-16.
ASSIS, O. B. G.; LEONI, A. M. Filmes comestíveis de quitosana. Revista Biotecnologia, Ciência e Desenvolvimento, Uberlândia, n. 30, p.33-38, 2003.

CARO, Y.; JOAS, J. Postharvest control of litchi pericarp browning (cv. Kwai Mi) by combined treatments of chitosan and organics acids II. Effect of the initial water content of pericarp. Postharvest Biology and Technology, Amsterdam, v.38, n.1, p.137-144, 2005.

CHAIPRASART, P. Effect of modified atmosphere packaging by $\mathrm{PE}$ and PVC on quality changes of lychee fruits. Acta Horticulturae, The Hague, n. 665, p. 379-380, 2005.

CHITARRA, M. I. F.; CHITARRA, A. B. Pós-colheita de frutos e hortaliças: fisiologia e manuseio. 2.ed. Lavras: Editora UFLA, 2005. 783 p.

DUCAMP-COLLIN, M.; RAMARSON, H.; LEBRUN, M.; SELF, G.; REYNES, M. Effect of ciric and chitosan on maintaining red colouration of litchi fruit pericarp. Postharvest Biology and Technology, Amsterdam, v. 49, p. 241-246, 2008. 
FONTES, V. L.; MOURA, M. A.; VIEIRA, G.; FINGER, F. L. Efeito de filmes plásticos e temperatura de armazenamento na manutenção da cor do pericarpo de lichia (Litchi chinensis). Revista Brasileira de Armazenamento, Viçosa, MG, v. 24, n. 1, p. 56$59,1999$.

FOYER, C. H.; DESCOURVIERES, P.; KUNERT, K. J. Protection against oxygen radicals: An important defense mechanism studied in transgenic plants. Plant Cell and Environment, Malden, v. 17, p. 507-523, 1994.

FRANCIS, F.J. Analysis of anthocyanins. In: MARKAKIS, P. (Ed.). Anthocyanins as food colors. New York: Academic Press, 1982. p.181-207.

HOLCROFT, D. M.; MITCHAM, E. J. Review: postharvest physiology and handling of litchi (Litchi chinensis Sonn.). Postharvest Biology and Technology, Amsterdam, v.9, n.1, p.265-281, 1996.

JOAS, J.; CARO, Y.; DUCAMP, M. N.; REYNES, M. Postharvest control of pericarp browning of litchi (Litchi chinensis Sonn cv. Kwai Mi) by treatment with chitosan and organic acids I. Effect of $\mathrm{pH}$ and pericarp dehydration. Postharvest Biology and Technology, Amsterdam, v. 38, p. 128-136, 2005.

KADER, A.A. Modified and controlled atmosphere storage of tropical fruits. In: CHAMP, B.R., HIGHLEY, E., JOHNSON, G.I. (Ed.). Postharvest handling of tropical fruit. Ganberra: ACIAR, 1994, v.50, p. 239-249.

KESTER, J.J.; FENNEMA, O. R. Edible films and coatings: A review. Food Technology, Chicago, v. 42, p. 47-59, 1988.

LIMA, G.P.P.; BRASIL, O.G.; OLIVEIRA, A.M. Poliaminas e atividade da peroxidase em feijão ( $P h a-$ seolus vulgaris L.) cultivado sob estresse salino. Scientia Agrícola, Piracicaba, v.56, n.1, p.21- 25, 1999.

PECH, J. C. Unravelling the mechanisms of fruit ripening and development of sensory quality thought the manipulation of ethylene biosynthesis in melon. In: NATO ADVANCED RESEARCH WORKSHOP ON BIOLOGY AND BIOTECHNOLOGY OF THE PLANT HORMONE ETHYLENE, 2002, Murcia. Anais...
PESIS, E.; DVIR, O.; FEYGENBERG, O.; BEN ARIE, R.; ACKERMAN, M.; LICHTER, A. Production of acetaldehyde and ethanol during maturation and modified atmosphere storage of litchi fruit. Postharvest Biology and Technology, Amsterdam, v. 26, p. 157-165, 2002.

RANGANNA, S. Manual of analysis of fruit and vegetable products. New Delhi: McGraw-Hill, 1977. 634p.

SALTVEIT, M. E. Procedures for extracting and analyzing internal gas samples from plant tissues by gas chromatography. HortScience, Alexandria, v. 17, n. 6 , p. $878-881,1982$.

SCOTT, K. J.; BROWN, B. I.; CHAPLIN, G. R.; WILCOX, M. E.; BAIN, J. M. The control of rotting and browning of litchi fruit by hot benomyl and plastic film. Scientia Horticulturae, Amsterdam, v.16, p.253-262, 1982.

SIVAKUMAR, D.; ARREBOLA, E.; KORSTEN, L. Postharvest decay control and quality retention in litchi (cv. MacLean's Red) by combined application of modified atmosphere packaging and antimicrobial agents. Crop Protection, Madison, v. 27, p. 12081214, 2008.

SOMBOONKAEW, N.; TERRY, L. A. Physiological and biochemical profiles of imported litchi fruit under modified atmosphere packaging. Postharvest Biology and Technology, Amsterdam, v. 56, p. 246253, 2010a.

SOMBOONKAEW, N.; TERRY, L. A. Influence of temperature and packing on physiological and chemical profiles of imported litchi fruit. Food Research International, Bedfordshire,v.44, n.7, p.1962-1969, 2010b.

TAYLOR, J. E. Exotics. In: SEYMOUR, G. B.; TAYLOR, J. E.; TUCKER, G. A. Biochemistry of fruit ripening. Cambridge: Chapman \& Hall, 1993. p.151-187.

UNDERHILL, S.J.R.; COATES, L.M.; SAKS, Y.; Litchi. In: MITRA, S.K. (Ed.). Postharvest physiology and storage of tropical and subtropical fruits. London: CAB International, 1997. p.191-208.

ZHANG, D.; QUANTICK, P. C. Effects of chitosan coating on enzymatic browning and decay during postharvest storage of litchi (Litchi chinensis Sonn.) fruit. Postharvest Biology and Technology, Amsterdam, v. 12, p. 195-202, 1997. 